\title{
FAKTOR PENYEBAB KECELAKAAN KERJA DI PT. TAPIOKA TEGUH WIBAWA BAKTI PERSADA LAMPUNG UTARA
}

\author{
Dewi Novita Sari ${ }^{1}$
}

\begin{abstract}
Abstrak
Kecelakaan kerja disebabkan oleh faktor manusia dan faktor lingkungan Faktor manusia meliputi, kurang pendidikan, menjalankan pekerjaan tanpa mempunyai kewenangan dan tidak sesuai keahlian, pemakaian alat pelindung diri, bekerja melebihi jam kerja. Sedangkan faktor lingkungan meliputi peralatan yang tidak layak pakai, terdapat api di tempat bahaya, pengamanan gedung yang kurang standar, pencahayaan, kebisingan.

Tujuan penelitian untuk mengetahui gambaran faktor penyebab kecelakaan kerja di PT Tapioka Teguh Wibawa Bakti Persada Kecamatan Blambangan Pagar Kabupaten Lampung Utara. Variabel yang diteliti adalah penggunaan alat pelindung diri (APD), waktu kerja, pencahayaan dan kebisingan. Penelitian bersifat deskriptif yang melibatkan seluruh pekerja bagian produksi, sebanyak 70 orang, Pengumpulan data dengan pengukuran, observasi dan wawancara.

Hasil penelitian mendapatkan bahwa tingkat penggunaan APD pada pekerja masih rendah, berkisar antara $25,7-64,3 \%$. Hasil pengukuran intensitas pencahayaan belum sesuai dengan persyaratan, dan intensitas kebisingan telah melebihi NAB yang diperbolehkan. Perlu upaya pengendalian untuk menghindari terjadinya gangguan kesehatan dan kecelakaan kerja.
\end{abstract}

Kata kunci: APD, pencahayaan, kebisingan, risiko kerja, tapioka

1) Alumni Jurusan Kesehatan Lingkungan Poltekkes Kemenkes Tanjungkarang

\section{PENDAHULUAN}

Pembangunan nasional mengalami perkembangan sangat pesat dalam beberapa dasawarsa terakhir. Sentra-sentra industri bertumbuhan sebagai satu kekuatan ekonomi yang memerlukan kualitas sumber daya manusia (SDM) pekerja kreatif dan inovatif, sehingga menghasilkan out put berkualitas dan kompetitif di pasar global. Pada situasi ini kebutuhan keselamatan dan kesehatan kerja (K3) merupakan hal terpenting dalam menunjang produktivitas kerja.

Menurut Undang-Undang Nomor 1 Tahun 1970 pada pasal 13 menyebutkan bahwa setiap orang akan memasuki tempat kerja, diwajibkan mentaati semua petunjuk keselamatan kerja dan memakai alat-alat perlindungan diri yang diwajibkan. Sedangkan menurut UndangUndang Nomor 13 Tahun 2003 pasal 86 ayat 2a menyebutkan bahwa setiap pekerja/buruh memiliki hak untuk mendapatkan perlindungan keselamatan dan kesehatan kerja. Sehingga diperlukan upaya Keselamatan dan Kesehatan Kerja (K3) melalui upaya pencegahan kecelakaan dan penyakit akibat kerja, pengendalian bahaya di tempat kerja, promosi kesehatan, pengobatan, dan rehabilitasi.

Kecelakaan kerja disebabkan oleh faktor manusia dan faktor lingkungan Faktor manusia meliputi a) ketidakseimbangan fisik tenaga kerja; b) kurang pendidikan; c) menjalankan pekerjaan tanpa mempunyai kewenangan; d) menjalankan pekerjaan yang tidak sesuai dengan keahliannya; e) pemakaian alat pelindung diri; f) mengangkut beban yang berlebihan; g) bekerja berlebihan atau melebihi jam kerja. Sedangkan faktor lingkungan meliputi: a) peralatan yang sudah tidak layak pakai; b) ada api tempat bahaya; c) pengamanan gedung yang kurang standar; d) faktor fisik seperti pencahayaan, kebisingan, dan iklim kerja; e) sistem peringatan yang berlebihan; f) sifat pekerjaan yang mengandung potensi bahaya. Jumlah kecelakaan kerja (Zerro Accident) yang terjadi harus nihil pada kurun waktu tertentu (Anizar, 2012).

Data kecelakaan kerja di Indonesia (pada populasi tenaga kerja 7-8 juta) menunjukkan 100.000 peristiwa kecelakaan kerja dengan hilang hari kerja setiap tahunnya, kerugian ratarata sekitar Rp 100-200 milyar per tahunnya, 
korban meninggal per tahun rata-rata antara 1.500-2.000 orang. Khusus pada untuk tahun 2000, kecelakaan kerja mengakibatkan kehilangan 70 juta hari kerja atau sekitar 500 juta jam kerja. Jika terhadap angka-angka tersebut diambil asumsi bahwa populasi tenaga kerja sebanyak 50 juta orang, perbandingan biaya tersembunyi terhadap biaya langsung sebesar empat (4) berbanding satu (1), sedangkan perbandingan seluruh kecelakaan terhadap kecelakaan berat yang dilaporkan adalah 300 kali, maka kerugian yang dinyatakan dalam uang per tahunnya sebesar $\mathrm{Rp}$ 2 triliun atau kehilangan jam kerja 5 triliun jam kerja. Kerugian akibat kecelakaan kerja ini, jika dilakukan pencegahan dan berhasil, maka akan sangat besar dampaknya untuk menggerakan dunia usaha. Kerugian tersebut belum termasuk penyakit akibat kerja yang data statistiknya relative sangat minim, tetapi penelitian lapangan menunjukkan prevalensi yang cukup berarti (Suma'mur, 2014).

Pabrik Tapioka Teguh Wibawa Bakti Persada (TWBP) Kecamatan Blambangan Pagar Kabupaten Lampung Utara merupakan pabrik tapioka yang bergerak di bidang pengolahan singkong menjadi tepung tapioka. Pabrik ini beroperasi selama 24 jam per hari, terdiri dari 3 shift yang masing-masing selama 8 jam kerja. Jumlah pekerja di bagian produksi setiap shift berjumlah 70 orang pekerja.

Berdasarkan data perusahaan, selama tahun 2015-2017 telah terjadi kecelakaan kerja sebanyak sembilan kali. Hasil studi awal diketahui bahwa sebagian pekerja di PT TWBP belum menggunakan alat pelindung diri (APD). Penelitian bertujuan untuk mendapatkan gambaran faktor penyebab kecelakaan kerja di Pabrik TWBP Kecamatan Blambangan Pagar Kabupaten Lampung Utara.

\section{METODE}

Jenis penelitian bersifat deskriptif untuk menggambarkan faktor penyebab kecelakaan kerja di pabrik tapioka PT Teguh Wibawa Bakti Persada Kecamatan Blambangan Pagar Kabupaten Lampung Utara. Penelitian dilaksanakan pada bulan Mei-Juni 2018. Populasi penelitian ini mengikutsertakan seluruh pekerja pada bagian produksi, sebanyak 70 pekerja.

Pengumpulan data dilakukan observasi, wawancara dan pengukuran. Observasi menggunakan checklist untuk mendapatkan data penggunaan APD, cara kerja, dan jam kerja. Metode wawancara dilakukan untuk mendapatkan informasi tambahan tentang faktor pekerja (pengetahuan, penggunaan APD) dan manajemen perusahaan (peraturan, pengawasan ketersediaan APD). Pengukuran kebisingan dilakukan dengan menggunakan Sound Level Meter, dan pencahayaan dengan Lux Meter. Analisis data dilakukan dengan membandingkan hasil pengumpulan data dengan Peraturan Menteri Kesehatan Republik Indonesia Nomor 70 Tahun 2016 tentang Standar dan Persyaratan Kesehatan Lingkungan Kerja Industri.

\section{HASIL}

\section{Penggunaan alat pelindung diri (APD)}

Pada Tabel 1 terlihat bahwa penggunaan APD pada pekerja bagian produksi di PT Tapioka Teguh Wibawa Bakti Persada masih rendah. Jumlah pekerja yang menggunakan helm saat bekerja sebanyak 22 orang (31\%), kaca mata sebanyak 30 orang $(42 \%)$, perisai muka sebanyak 25 orang (35\%), penutup telinga sebanyak 27 orang (38\%), masker sebanyak 18 orang $(25 \%)$, sarung tangan sebanyak 44 orang (62\%), sepatu kerja sebanyak 38 orang (54\%), dan menggunakan pakaian kerja sebanyak 28 orang $(40 \%)$.

Tabel 1. Distribusi Responden Berdasarkan Penggunaan APD

\begin{tabular}{lccccl}
\hline \multirow{2}{*}{ Jenis APD } & \multicolumn{4}{c}{ Penggunaan APD } & \\
\cline { 2 - 5 } & \multicolumn{3}{c}{ Ya } & \multicolumn{3}{c}{ Tidak } & \\
\cline { 2 - 5 } & $\mathrm{n}$ & $\%$ & $\mathrm{n}$ & $\%$ & \multirow{2}{*}{ Keterangan } \\
\hline Helm & 22 & 31,4 & 48 & 68,6 & Penggerak traktor, bagian mesin/bengkel \\
Kaca Mata & 30 & 42,9 & 40 & 57,1 & Bagian mesin/bengkel \\
Perisai Muka & 45 & 64,3 & 25 & 35,7 & Oven, penggilingan. \\
Penutup Telinga & 27 & 38,6 & 43 & 61,4 & Oven, penggilingan. \\
Masker & 18 & 25,7 & 52 & 74,3 & Oven, penggilingan. \\
Sarung Tangan & 44 & 62,9 & 26 & 37,1 & Ceker, oven, penggilingan, penimbangan. \\
Sepatu Kerja & 38 & 54,3 & 32 & 45,7 & Mesin, penggilingan, oven, penggerak traktor \\
Pakaian Kerja & 28 & 40,0 & 42 & 60,0 & Kasir, ceker bongkol, bagian bengkel/mesin. \\
\hline
\end{tabular}




\section{Waktu Kerja}

Dari Tabel 2 dapat diketahui bahwa seluruh pekerja (100\%) di bagian Produksi di PT
Tapioka Teguh Wibawa Bakti Persada Kecamatan Blambangan Pagar Lampung Utara bekerja selama delapan jam per hari.

Tabel 2. Distribusi Responden Berdasarkan Jam Kerja

\begin{tabular}{clccl}
\hline No & \multicolumn{1}{c}{ Jam Kerja } & $\mathrm{n}$ & $\%$ & \multicolumn{1}{c}{ Keterangan } \\
\hline 1 & Baik $\leq 8$ Jam & 70 & 100,0 & Peraturan Menteri Kesehatan RI Nomor 70 Tahun 2016 \\
2 & Kurang Baik > 8 jam & 0 & 0,0 & $\begin{array}{l}\text { tentang Standar dan Persyaratan Kesehatan Lingkungan } \\
\text { Kerja Industri }\end{array}$ \\
\hline
\end{tabular}

\section{Pencahayaan}

Dari Tabel 3 dapat diketahui bahwa pencahayaan pada ruang penggilingan sebesar 130 Lux, dan ruang oven 160 Lux. Hasil pengukuran ini menunjukkan bahwa intensitas pencahayaan di ruang produksi PT Tapioka Teguh Wibawa Bakti Persada belum memenuhi standar, yaitu 200 Lux.

Tabel 3. Hasil Pengukuran Pencahayaan Pada Ruang Produksi

\begin{tabular}{|c|c|c|c|}
\hline Ruangan & Pengukuran & Standar & Keterangan \\
\hline Ruang Penggilingan & 130 Lux & 200 Lux & Peraturan Menteri Kesehatan RI Nomor 70 \\
\hline Ruang Oven & $160 \mathrm{Lux}$ & 200 Lux & $\begin{array}{l}\text { Tahun } 2016 \text { tentang Standar dan Persyaratan } \\
\text { Kesehatan Lingkungan Kerja Industri }\end{array}$ \\
\hline
\end{tabular}

\section{Kebisingan}

Pada Tabel 3 dapat diketahui bahwa intensitas kebisingan pada ruang penggilingan sebesar 89,7 dBA, dan ruang oven 87,1 dBA. Hasil pengukuran ini menunjukkan bahwa intensitas kebisingan di ruang produksi PT Tapioka Teguh Wibawa Bakti Persada telah melebihi standar yang diperbolehkan, yaitu 85 dBA.

Tabel 4. Hasil Pengukuran Tingkat Kebisingan Pada Ruang Produksi

\begin{tabular}{lccl}
\hline \multicolumn{1}{c}{ Ruangan } & Pengukuran & NAB & \multicolumn{1}{c}{ Keterangan } \\
\hline Ruang Penggilingan & $89,7 \mathrm{dBA}$ & $85 \mathrm{dBA}$ & Peraturan Menteri Kesehatan RI Nomor 70 \\
Ruang Oven & $87,1 \mathrm{dBA}$ & $85 \mathrm{dBA}$ & $\begin{array}{l}\text { Tahun 2016 tentang Standar dan Persyaratan } \\
\text { Kesehatan Lingkungan Kerja Industri }\end{array}$ \\
\hline
\end{tabular}

\section{PEMBAHASAN}

\section{Penggunaan alat pelindung diri (APD)}

Berdasarkan Tabel 1 diketahui bahwa penggunaan APD pada pekerja di PT Tapioka Teguh Wibawa Bakti Persada masih kurang baik. Kurang dari separuh pekerja tidak menggunakan perisai muka (35\%), sarung tangan (37\%), dan sepatu kerja (46). Sisanya telah memakai, walaupun kurang dari $70 \%$, yaitu helm (68\%), kaca mata (57\%), penutup telinga (61\%), dan masker (74\%).

Rendahnya penggunaan APD pada pekerja dipengaruhi oleh beberapa faktor, yaitu kurangnya pengetahuan tentang pentingnya APD, tidak adanya peraturan yang tegas dari perusahaan, tidak ada rambu peringatan bahaya kecelakaan kerja, dan ketidaknyamanan dalam penggunaan APD. Rendahnya kesadaran pekerja dalam penggunaan APD dapat berakibat pada kecelakaan kerja. Hal ini disebabkan oleh kebiasaan pekerja dalam penggunaan APD susah untuk diubah. Selain APD rusak, sebagian pekerja merasa tidak nyaman saat menggunakan APD. Keluhan yang disampaikan pekerja tentang APD antara lain kendur, robek, panas saat dipakai, dan mengganggu pekerjaan.

Namun penelitian ini tidak sesuai dengan penelitian di PT Jamu Air Mancur yang mengemukakan bahwa responden merasa nyaman dengan pelindung diri yang mereka pakai. Kenyamanan timbul karena mereka merasa tidak terganggu dalam pemakaian APD tersebut dan sudah terbiasa memakai, sehingga kenyamanan muncul dengan sendirinya (Swaputri, 2009). 
Menurut Riyadina et al (2007), pekerja yang menggunakan APD tidak sesuai akan beresiko 2,2 kali mengalami kecelakaan kerja dibandingkan menggunakan APD yang sesuai. Sehingga, pemakaian APD yang tidak tepat dianggap membahayakan atau menambah resiko kecelakaan kerja (Prasetyo, 2016).

\section{Jam Kerja}

Berdasarkan Tabel 2 diketahui bahwa seluruh pekerja di bagian produksi PT Tapioka Teguh Wibawa Bakti Persada bekerja selama delapan jam per hari. Jumlah jam kerja telah sesuai dengan Peraturan Menteri Kesehatan RI Nomor 70 Tahun 2016 tentang Standar dan Persyaratan Kesehatan Lingkungan Kerja Industri.

Hasil penelitian ini tidak sesuai dengan penelitian Fitriyati (2009) di PT. X Cikarang, Jawa Barat yang menyebutkan adanya hubungan antara lama waktu kerja dengan kejadian kecelakaan. Hasil penelitian lain juga menyebutkan bahwa salah satu faktor risiko kecelakaan kerja adalah lama waktu kerja (Jawawi, 2008).

\section{Pencahayaan}

Berdasarkan hasil pengukuran, intensitas pencahayaan di ruang penggilingan sebesar 130 Lux dan di ruang oven sebesar 160 Lux. Hasil menunjukkan bahwa intensitas pencahayaan di ruang produksi PT Tapioka Teguh Wibawa Bakti Persada belum memenuhi persyaratan. Menurut Peraturan Menteri Kesehatan RI Nomor 70 Tahun 2016 tentang Standar dan Persyaratan Kesehatan Lingkungan Kerja Industri, standar pencahayaan di ruang kerja sebesar 200 Lux.

Agar pencahayaan memenuhi persyaratan kesehatan, maka beberapa tindakan yang perlu dilakukan antara lain :

a. Pencahayaan alam maupun buatan diupayakan agar tidak menimbulkan efek silau dan memiliki intensitas sesuai dengan peruntukannya.

b. Kontras sesuai kebutuhan, hindarkan terjadinya kesilauan atau bayangan.

c. Untuk ruang kerja yang menggunakan peralatan berputar dianjurkan untuk tidak menggunakan lampu neon.

d. Penempatan bola lampu dapat menghasilkan penyinaran yang optimum dan bola lampu sering dibersihkan.

e. Bola lampu yang mulai tidak berfungsi dengan segera diganti.

\section{Kebisingan}

Hasil penelitian mendapatkan bahwa intensitas kebisingan pada ruang penggilingan sebesar 89,7 dBA, dan ruang oven 87,1 dBA. Menurut Peraturan Menteri Kesehatan RI Nomor 70 Tahun 2016 tentang Standar dan Persyaratan Kesehatan Lingkungan Kerja Industri, nilai ambang batas (NAB) kebisingan untuk masa paparan 8 jam/hari adalah $85 \mathrm{dBA}$. Hasil pengukuran ini menunjukkan bahwa intensitas kebisingan di ruang produksi PT Tapioka Teguh Wibawa Bakti Persada telah melebihi NAB yang diperbolehkan.

Kebisingan merupakan salah satu faktor risiko lingkungan kerja yang dapat menimbulkan gangguan kesehatan dan kecelakaan kerja. Kebisingan merupakan semua suara yang tidak dikehendaki yang bersumber dari alat-alat proses produksi dan/atau alat-alat kerja yang pada tingkat tertentu dapat menimbulkan gangguan pendengaran. Hubungan antara kebisingan dengan timbulnya gangguan kesehatan dipengaruhi oleh faktor intensitas kebisingan dan lamanya paparan per hari.

Telah disampaikan bahwa seluruh pekerja di ruang produksi PT Tapioka Teguh Wibawa Bakti Persada bekerja selama 8 jam per hari, sehingga lama paparan kebisingan selama 8 jam per hari. Tingginya intensitas kebisingan berdasarkan waktu paparan per hari, akan memberikan dampak terhadap kesehatan pekerja. Dampak kesehatan fisiologis berupa sakit kepala, mual, meningkatnya denyut nadi dan tekanan darah, hingga gangguan pendengaran. Sedangkan dampak psikologis antara lain ketidaknyamanan, hilangnya konsentrasi, gangguan tidur, dan peningkatan emosi.

Pengendalian kebisingan dapat dilakukan dalam tiga bentuk pengendalian, yaitu:

a. Pengendalian secara teknik.

Pengendalian secara teknik dilakukan setelah bising teridentifikasi melalui hasil pengukuran dan analisis kebisingan. Konsep pengendalian pada dasarnya adalah mengurangi paparan terhadap pekerja dengan mengendalikan dua komponen, yaitu mengurangi kebisingan pada tingkat sumber dan menghilangkan transmisi kebisingan terhadap manusia.

Beberapa tindakan mengurangi pada tingkat sumber, antara lain: 1) melakukan pemeliharaan dan pelumasan mesin-mesin dengan teratur; 2) pemilihan dan 
penggunaan mesin dengan tingkat kebisingan rendah. Sedangkan tindakan pada transmisi, antara lain: 1) menutup atau menyekat mesin atau alat yang mengeluarkan bising; 2) Mengurangi bunyi yang diterima pekerja; 3) pemasangan bantalan peredam pada alas mesin; 3) Penggunaan alat pelindung telinga untuk menurunkan intensitas kebisingan yang mencapai alat pendengaran.

b. Pengendalian secara administratif

Pengendalian secara administratif merupakan prosedur yang bertujuan untuk mengurangi waktu paparan pekerja terhadap bising, dengan merotasi dan menyusun jadwal kerja berdasarkan perhitungan dosis paparan sesuai $\mathrm{NAB}$, pemeriksaan kesehatan awal, berkala maupun pemeriksaan kesehatan secara khusus, penerapan sanksi.

c. Pengendalian dengan APD

Penggunaan APD adalah upaya terakhir apabila secara teknis dan administratif tidak dapat mengurangi paparan kebisingan. Terdapat dua jenis alat perlindungan telinga, yaitu ear muff dan ear plug. Sumbat telinga atau ear plugs adalah pelindung yang dimasukkan ke dalam liang telinga sehingga suara tidak mencapai membran timpani. Kemampuan sumbat telinga mengurangi bising sekitar $30 \mathrm{~dB}$, digunakan untuk kebisingan berkisar antara 85-200 dBA. Tutup telinga atau ear muff menutupi seluruh telinga eksternal dan mampu mengurangi bising 40-50 dBA. Pemilihan earmuff jika kebisingan di atas $100 \mathrm{dBA}$.

\section{KESIMPULAN}

Penelitian mendapatkan bahwa tingkat penggunaan APD masih rendah, berkisar antara 25,7-64,3\%. Hasil pengukuran intensitas kebisingan telah melebihi NAB, yaitu sebesar 89,7 dBA dan 87,1 dBA. Demikian pula hasil pengukuran intensitas pencahayaan, juga belum sesuai dengan standar yang ditetapkan (130 Lux dan 160 Lux). Rendahnya tingkat penggunaan APD serta nilai faktor risiko fisik yang tidak sesuai standar, dapat meningkatkan risiko gangguan kesehatan dan kecelakaan kerja. Oleh karena itu perlu tindakan pengendalian.

\section{DAFTAR PUSTAKA}

Anizar, 2012. Teknik Keselamatan dan Kesehatan Kerja di Industri, Graha Ilmu, Yogyakarta, 190 halaman.

Fitriyati R., Eka, 2009. Beberapa Faktor Yang Berhubungan Dengan Tingkat Kecelakaan Kerja Di Pt. X Cikarang Jawa Barat Tahun 2009. Thesis, Universitas Diponegoro.

Jawawi, Iskandar, 2008. Beberapa Faktor Resiko Yang Berhubungan Dengan Tingkat Kecelakaan Kerja Di Pt Hok Tong Pontianak (Pabrik Crum Rubber). Thesis, Universitas Diponegoro.

Peraturan Menteri Kesehatan RI Nomor 70 Tahun 2016 tentang Standar dan Persyaratan Kesehatan Lingkungan Kerja Industri

Prasetyo, Eko., Budiati, Risna Endah., 2016. Analisis Program Inspeksi Keselamatan Dan Kesehatan Kerja (K3) Sebagai Bentuk Upaya Promosi Budaya K3 Di Lingkungan Kerja. Jurnal Kesehatan Masyarakat Cendikia Utama Edisi Agustus 2016.

Suma'mur, 2014. Hygiene Perusahan dan Keselamatan Kerja, Sugeng Seto, Jakarta, 570 halaman.

Swaputri, Eka. 2009. Analisis Penyebab Kecelakaan Kerja (studi Kasus PT. Jamu Air Mancur). Skripsi Sarjana, Fakultas Ilmu Keolahragaan, Semarang. 